\title{
DC/DC Converter with Active Filter Supplied from Trolley Net
}

\author{
J. Sitar, V. Racek \\ Alexander Dubcek University of Trencin \\ Studentska 1, 91150, Trencin \\ Slovakia
}

\author{
P. Bauer \\ Delft University of Technology \\ Delft, Mekelweg 4, 2628 CD \\ The Netherlands
}

\begin{abstract}
Two different methods of an active filter design for a DC/DC converter with input active filter are presented. Offset method is designed for stabilization of the undesired current values on input choke and is focused on total changes of converter switching. Stabilization method with super-capacitor is oriented on input voltage compensation. Super-capacitor is used here as energy buffer for voltage drop compensation. Obtained results are compared and the realized measurement for offset method is presented.
\end{abstract}

\section{INTRODUCTION}

Active filter is usually used for output voltage stabilization of $\mathrm{DC} / \mathrm{DC}$ converters. DC/DC converters are in some cases such as traction supplied by an inductive power source. For this reason the active filter must be used for DC rail cars, train and tram applications.

High value of voltage fluctuations in trolley line have negative effect on frequency controlled asynchronous machine and input filter activities. Filter design must be proposed with elimination these undesirable influences. The basic circuit parameters for elimination of the following problems must be calculated:

- Filtering randomly occurring incipient voltage and current peaks. This results in destroying the filter choke or breaking down of capacitor,

- When the voltage decreases, it is necessary to reach desired value of voltage before the switcher by switching the transistor $\mathrm{T}_{1}$ (Fig.1 DC/DC converter is in buck mode),

- The same is valid for increasing of the voltage level before the switcher with the assistance of second transistor switching activity $\mathrm{T}_{2}$. In this case the higher value of output voltage is detected,

- Suitable choice of filter parameters enables elimination of the voltage fluctuation. This is valid mainly for values of choke inductance and capacitor dimensions. These values are appointed from filter calculation [9]

- Between very important parameters of filter design is the transistor switching frequency and duty cycle (PWM modulation). With this switching the voltage is regulated on the required level.

Tram motors are working in two basic modes: motor mode for driver it is possible to enter only ride command, generator mode - the energy is returning back to the trolley net. Very important mode during motors activity is braking. It is possibly realized by several methods. In our case the recuperative and resistive braking was used. The recuperative braking is used for state when the energy is returning back to the trolley line. For case when the energy can not return back to the trolley net the energy is waste in braking resistor (Fig.1). With this resistor the resistive braking was realized.

\section{BASIC FILTER DESIGN AND SIMULATION}

The principal circuit diagram of two quadrants DC/DC converter for traction application with input filter and its simulation model are presented in Fig.1.

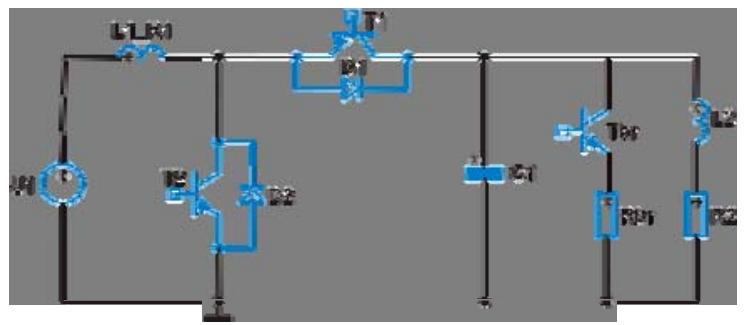

Fig. 1: Principal circuit diagram of DC/DC converter with active filter and various output load.

Based on this circuit diagram the simulations for wide range of input voltage and output load were performed. As a simulation tool the program CASPOC [18] for power electronic circuit simulation was selected.

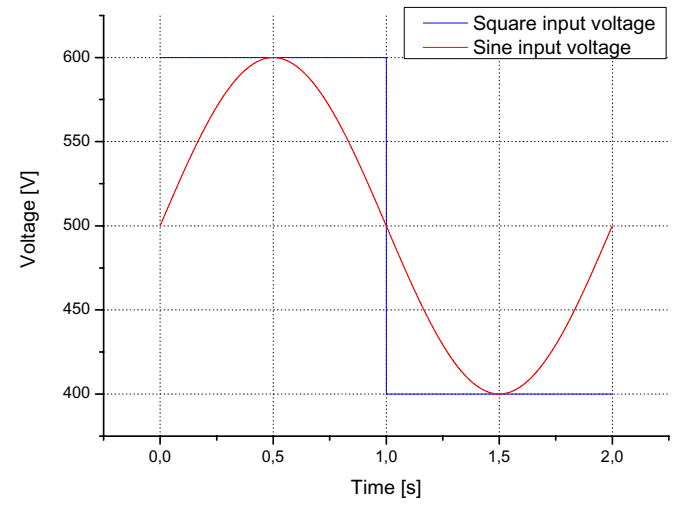

Fig. 2: Input trolley voltage waveforms. Red color - sinusoidal input voltage, blue color - square input trolley voltage.

In reality the fluctuation of input voltage in trolley line is between $400 \mathrm{~V}$ and $600 \mathrm{~V}$ and it depends on trams activity. For 
further investigation two different typical trolley input voltage variations are considered: square wave input voltage changing from $600 \mathrm{~V}$ to $400 \mathrm{~V}$ and sinusoidally changing input voltage (Fig.2).

The output load is changing in wide range too. The range of the output load is between $50 \mathrm{~kW}$ and $300 \mathrm{~kW}$. This load is in reality performed by a motor system. For simulation purposes the motor system can be simplified by a variable resistance and an inductor. This resistance is calculated on the base of equation.

$$
R_{2}=\frac{U_{2}}{I_{2}}=\frac{U_{2}^{2}}{P_{2}}
$$

With the equation (1) the simulations can be realized in variable power mode (in real system there are three asynchronous motors). A variable resistor $R_{2}$ course representing a typical load calculated with equation (1) for mentioned two input voltage variations is shown in Fig. 3.

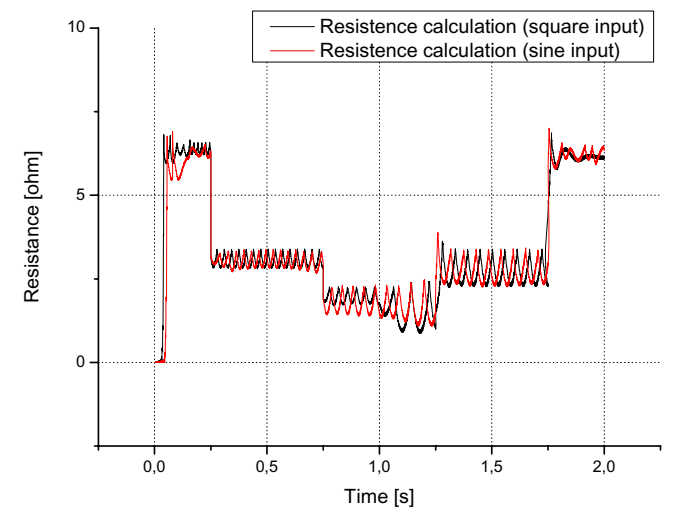

Fig. 3: Calculated resistance waveform during simulation process. Resistance is representing the variable output load.

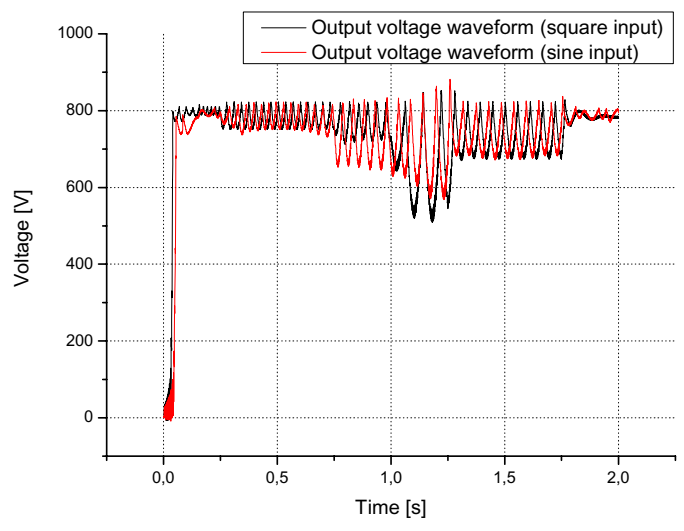

Fig. 4: Output voltage comparison of active filter. Red colour - input trolley voltage with sinusoidally changing waveform, blue colour - input trolley line with square waveform.

The switching frequency for IGBT transistor $\mathrm{T}_{2}$ is $400 \mathrm{~Hz}$ with duty cycle 0.8. In Fig.4 it is shown how the RLC circuit can behave and the output voltage variation for both input voltage variations and typical load is shown. The output voltage in this case is decreasing to a value of $500 \mathrm{~V}$. Similarly the current of the choke $\mathrm{L}_{1}$ under the same test conditions as previously is shown. The shapes of current curves have an aperiodical character and current is exceeding the value of the line switcher which is $750 \mathrm{~A}$.

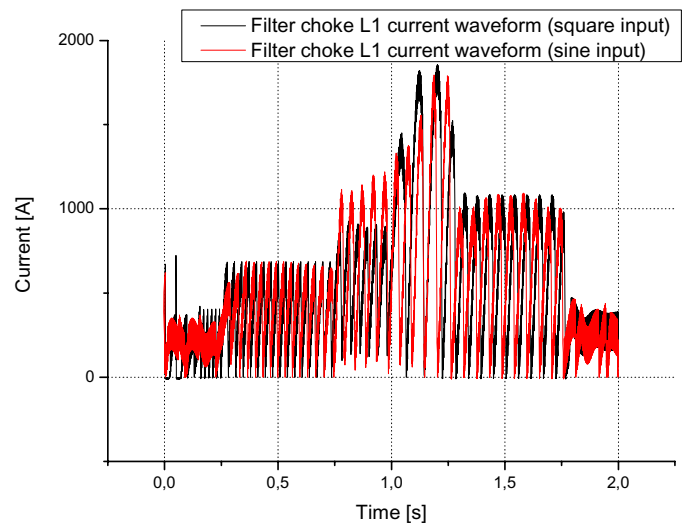

Fig. 5: Inductor current waveforms for different output load $(50 \mathrm{~kW}-$ $300 \mathrm{~kW})$.

During working process is necessary to eliminate the current spikes during time when the maximal load $(300 \mathrm{~kW})$ and minimal input trolley voltage $(400 \mathrm{~V})$ are active - drive mode. A solution is the significant control of the value of inductor current $\left(\mathrm{L}_{1}\right)$. Desiderative value for this current must be lower then turn - off current of the input link switcher (750A). Two different control methods are suggested further here:

- Offset method - nowadays this method is usually used in tram control systems. During activity of this method is undesirable value for input choke current eliminated by unplugging of the tram (converter) from the input trolley network. After that tram can only working in run - out mode (output voltage value is keeping with traction motor system on $800 \mathrm{~V}$ ). There is a not possibility for recuperative braking. Only resistive braking can be realized. During this time interval the driver can not engage the drive mode.

- Stabilization with the help of a super capacitors - in this relatively new method the ultra capacitors are used as an energy buffer. The cost of the ultra-capacitors is still decreasing and therefore this method is now widely used. In this solution the necessary energy is recharged from ultra-capacity energy buffer. This energy buffer is designed on optimal power and must provide the required amount of energy at the current and voltage ratio conservation during the input trolley voltage failure.

In designed control system for active dumping is necessary to realize many important states such as: drive, drifting, insulated state and short circuit. All these states are simulated for ideal tram way between two tram stops. The real tram can go through this cycle in 45 second. 


\section{OFFSET METHOD}

Offset method is designed for stabilization of undesired current values on input choke $\mathrm{L}_{1}$. A simple simulation circuit diagram of this method is shown in Fig. 6. Method is focused on the total changes of converter switching. During active damping the current waveform in the filter choke $L_{1}$ is measured. If the current value exceeds the desired value (in this case the value for input current of the line switcher $750 \mathrm{~A}$ ), the power supply is unplugged.

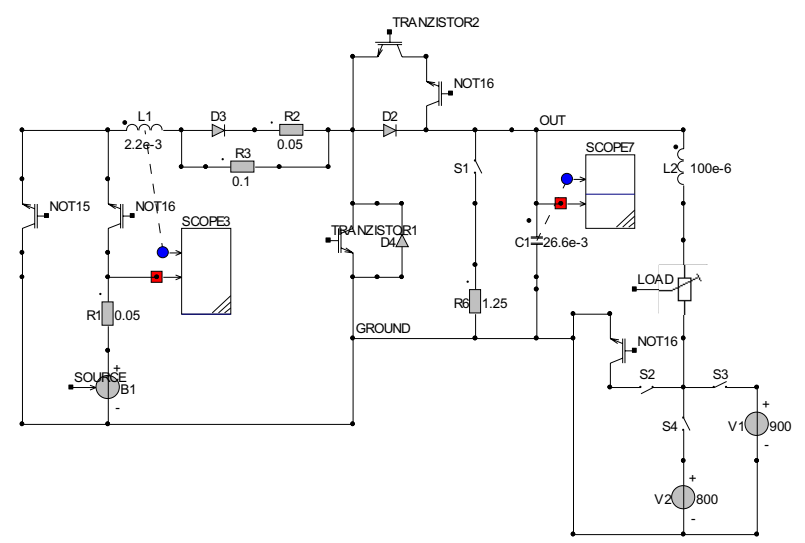

Fig. 6: Circuit diagram for active damping simulation during offset method.

It is necessary that the current flowing through the choke does not come over the line switcher value. If the value of the current comes exceeds the maximum value, the power supply unit is switched off so that a safe activity can be ensured. Afterwards it is necessary to notice that in this time there is no chance for recuperation. Recuperative transistor T2 is switched off or the control algorithm is set up so, that the transistor switching is made impossible during this situation.

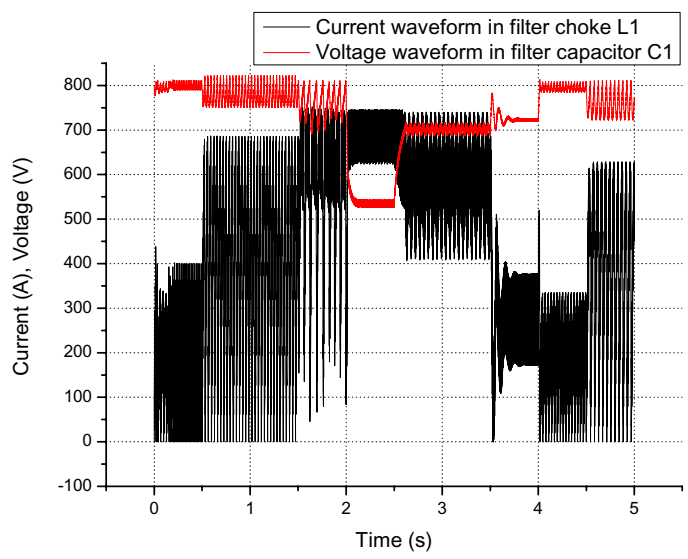

Fig. 7: The C1 voltage and L1 current waveforms. Lower waveform represented $\mathrm{L} 1$ current flow during the offset method. The current value increases to $740 \mathrm{~A}$ and decreases to $0 \mathrm{~A}$. Upper waveform presented the voltage on this capacitor. The voltage value varies from $550 \mathrm{~V}$ to $800 \mathrm{~V}$.

Results of the simulation during the typical load and square wave voltage change and with the application of the offset method are shown in Fig.7. Comparing the voltage drop during the use of the offset method (Fig.7) with the voltage drop without the offset method (Fig 4), one can see significant differences. It has to be noticed, that when the power source is disconnected, there is not possibility to drive and the driver cannot give this command. There are only two possibilities: the run-out mode and resistive braking. During run-out mode the voltage source V1 $(800 \mathrm{~V})$ is connected with presented load circuit in series. This is represented by the conditions in engines when no energy is needed from the power input and the tram is move only with own inertia. In this case also the resistive braking mode is possible but there is no chance for recuperative braking. There is only one possibility to spend the excessive energy into the braking resistor.

It is necessary for the gathered energy in the choke L1 can flow away while the power supply is disconnected. The filter choke should be connected to the ground which forms a short - circuit state. The transistor T1 is kept in an active mode for discharging of filter choke L1.

A comparison of inductor current for both typical voltage variations as presented in Fig. 5 with the use of offset method is shown in Fig. 9. There is no significant difference in the shape of both currents.

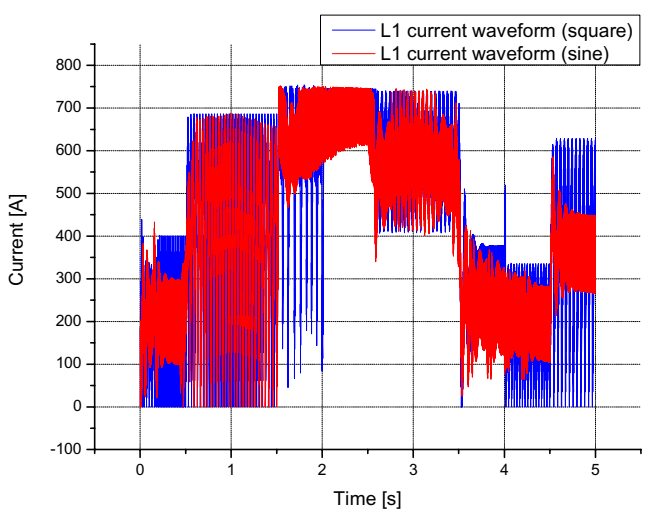

Fig. 9: Comparison of inductor current waveforms during offset method. Red colour - sinusoidal input voltage, blue colour - square input voltage waveform.

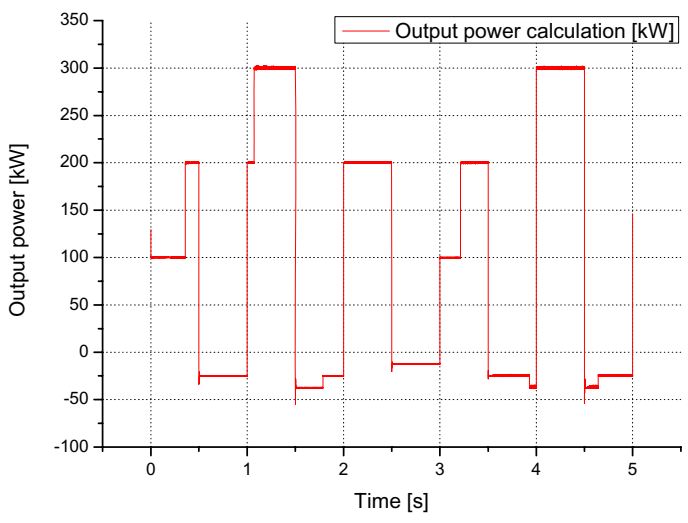

Fig. 10: Typical load pattern with the recuperation 


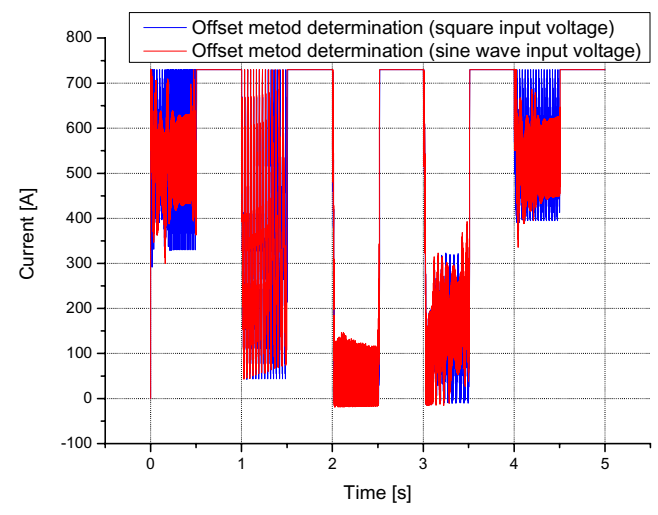

Fig. 11: Waveform is presented active state for the offset method. This method is active when the value of the current decreases below zero. The result is given as a comparison between required value of maximum current and real current value measured on the filter choke $L_{1}$.

Up to now the offset method without recuperation was presented. In the next step the simulation for recuperative mode is created for a typical load pattern with recuperation as shown in Fig. 10. This state is adjusted with voltage source connection. A $900 \mathrm{~V}$ voltage source is connected with output load in series. The output value of this source must be during recuperation higher as desired output voltage value. For this reason the $900 \mathrm{~V}$ value was chosen. During real recuperation the value of this voltage is changing and is dependent on motor revolution (Fig. 11).

\section{STABILIZATION METHOD WITH USE OF SUPERCAPACITOR}

This method is oriented on input voltage compensation mainly during time when the voltage value is decreasing on $400 \mathrm{~V}$. During this value of input link voltage the boost converter can not step up on output desired voltage (output voltage value is decreasing to $600 \mathrm{~V}$ at maximum output load of $300 \mathrm{~kW})$.

As a solution for this voltage absence it is possible to use the new method which is based on supplying of required voltage quantity from energy buffer. As energy buffer can be used ultra-capacitor. With this it is possible to stabilize the output voltage drop.

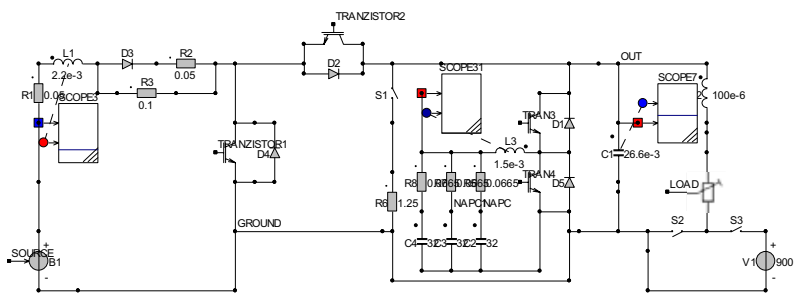

Fig. 12: Input simulation block diagram without control system for super - capacitance converter connection. Range for variable output load is from $50 \mathrm{~kW}$ to $300 \mathrm{~kW}$ and input voltage have range between $400 \mathrm{~V}$ and $600 \mathrm{~V}$. Ultra-capacitor is charged and discharged by second buck-boost converter.
Calculation of parameters for ultra-capacitor basic dimensions, circuit connection, resistance and capacitance are described in [1, 4 and 5]. During super-capacity energy buffer design we can not forget the way how it is possible to realized its charging and discharging (usually is realized by buck-boost converter).

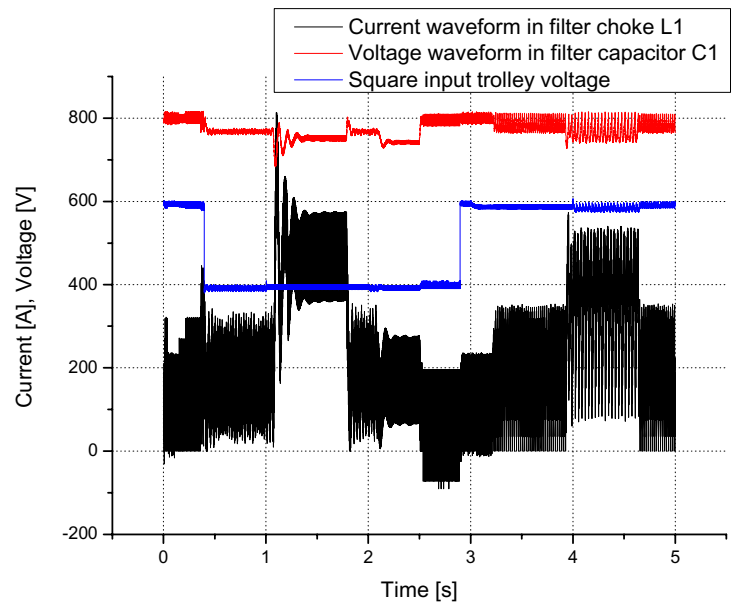

Fig. 13: Voltage and current waveforms on filter capacitor C1. Upper waveform presented range for output voltage from $700 \mathrm{~V}$ to $800 \mathrm{~V}$. Lower waveform presented capacitor current. His range is between $-700 \mathrm{~A}$ and $+700 \mathrm{~A}$. The current value was acquired as summarization from converter current and super-capacitor current value.

The way for complete super-capacitor design with required power during input voltage drop is presented in $[2,3]$. For super-capacitor energy bank charging another buck-boost converter must be used. Its switching frequency is around $800 \mathrm{~Hz}$ and variable duty cycle is from 0.1 to 0.95 . Modified circuit diagram with ultra-capacitor is presented in Fig. 12 together with charging converter and active dumping control system.

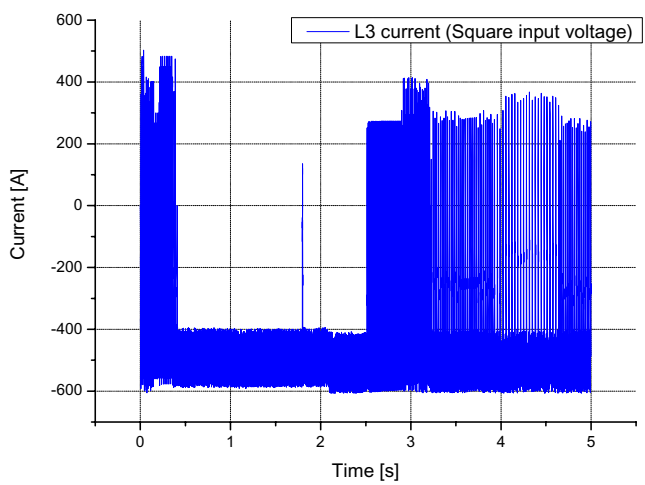

Fig. 14: Current running through ultra-capacitor converter choke $\mathrm{L}_{3}$. Current range is between -600A (for discharging mode) and $+600 \mathrm{~A}$ (for charging mode).

Main circuit diagram for simulation is presented in Fig. 12. Output waveforms for square input voltage change are shown in Fig. 13. Comparing both methods (Fig.13 and Fig.7) one can observe that for the super-capacitor stabilization the 
output voltage is stabilized and current does not reach high values.

Analysis of active dumping for DC/DC converter is oriented on current peaks and output voltage drops elimination during converter activity $[11,12]$. In this case the super-capacitor method was used for stabilization of output voltage waveforms. With aim of super-capacity the current through choke $\mathrm{L}_{1}$ is decreasing from $1.2-1.4 \mathrm{kA}$ to $750-780 \mathrm{~A}$. Analysis was created without generator mode for motor system. More specific simulation results are presented in the next step where the simulation with generator motor mode was calculated.

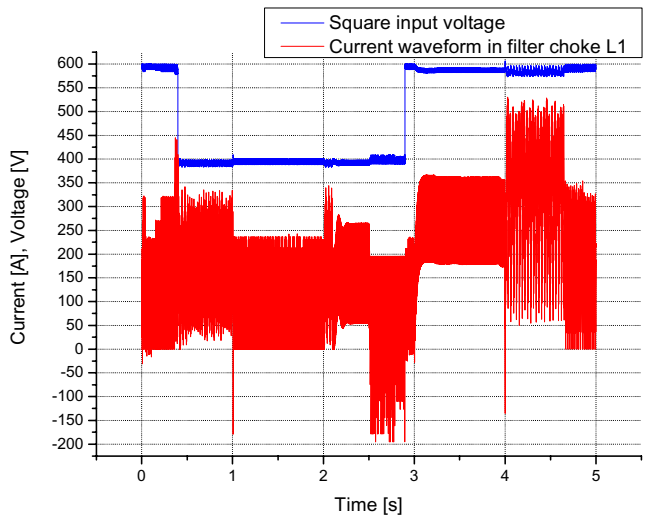

Fig. 15: Current and voltage waveforms for input filter choke L1. In analysis the variable output load $(50 \mathrm{~kW}-300 \mathrm{~kW})$ and generator mode was used. Upper waveform is presented input network voltage and lower waveform current running through filter choke. This current is between $200 \mathrm{~A}$ and $+550 \mathrm{~A}$.

The maximum current value for filter choke L1 is decreasing under 750A (maximum current for link switcher). Current waveform through filter choke $\mathrm{L}_{1}$ is presented in Fig. 15 .

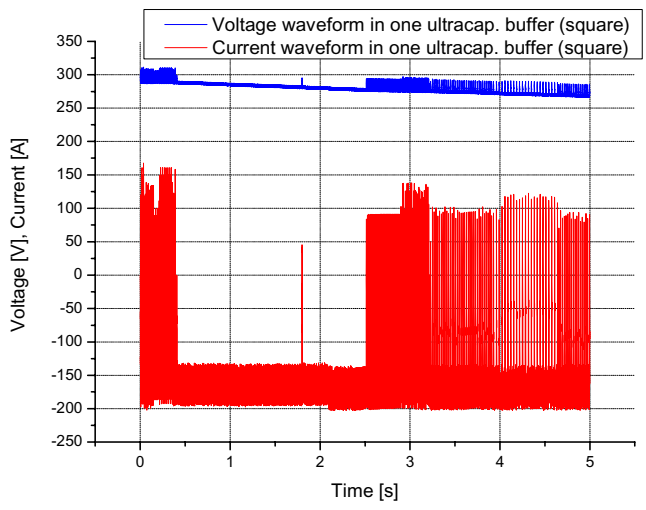

Fig. 16: Current and voltage running through one ultra-capacitor bank in parallel connection (square input trolley voltage). The current range is between -200A (for discharging time) and 165A (for charging time) and voltage is decreasing from $300 \mathrm{~V}$ to $260 \mathrm{~V}$.

In Fig. 16 the waveforms for ultra capacity discharging and charging voltage is presented. Charging is realized during generator and recuperation mode. Maximum super- capacitor voltage is $300 \mathrm{~V}$. Charging can be realized during recuperation mode and resistive breaking mode too. Choke current and output voltage waveforms are same as in previous case Fig. 13 (the maximum and minimum current and voltage value are very similar).

\section{STABILIZATION METHODS COMPARISION}

From obtained results for output voltage and current through filter choke can be seen the stabilization effect for the active filter simulation. In the next is necessary comparing the most important waveforms. In our case the filter capacitor voltage and input choke current are compared for different stabilization methods.

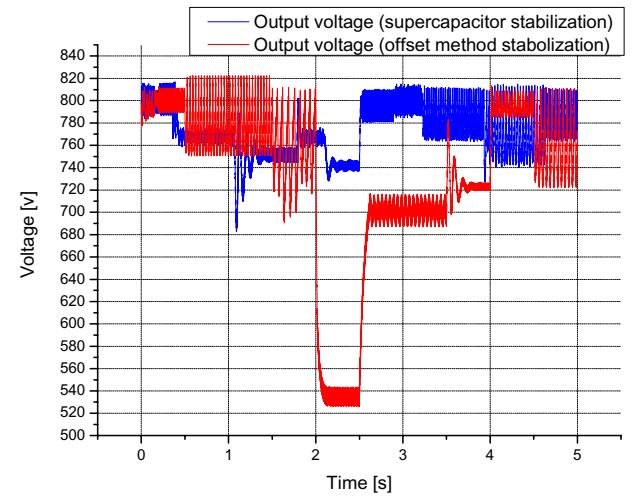

Fig. 17: Output voltage comparison. Red colour - offset stabilization method, blue colour - ultra-capacitor stabilization method.

In Fig. 17 the output voltage comparison is presented. In offset method simulation the voltage is decreasing to $520 \mathrm{~V}$. In the same time the maximum output load is connected. Compared to the super-capacitor stabilization method the output voltage is decreasing only to $680 \mathrm{~V}$.

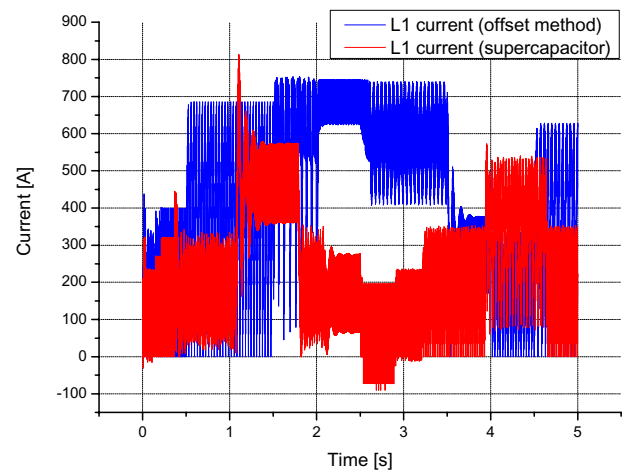

Fig. 18: L1 choke current waveforms comparison. Blue colour - offset stabilization method, red colour - ultra-capacitor stabilization method.

Filter choke L1 current comparison is presented in Fig. 18. In presented waveforms can be seen bigger differences. First difference is in the current spike for ultra-capacitor simulation (810A). This current spike can create trouble for input current protection circuit. Compared to the offset stabilization method the current waveform is less then 700A. The next differences are in time when the offset method is 
active and the choke current is coupe in value 740A. During super-capacitor stabilization method current value is decreasing under $300 \mathrm{~A}$. The main cause of this effect is infusion of necessary power from energy buffer. In short the power needed for the start is not provided by the distribution network (input trolley line), but is provided by the supercapacitor power tank. The target is to reduce the inrush current in the line by providing it thanks to the supercapacitor tank during the start of the tram, to limit the voltage drop.

\section{EXPERIMENTAL RESULTS}

For presented simulation results, the technical design of the active filter in $\mathrm{DC} / \mathrm{DC}$ converter has good preconditions for successful technical realization [11]. Based on this, the physical model of this converter was realized. The final measurement was realized for real tram T3 MOD 7304 (Fig. 19). The technical realization and measurements are created in Electrotechnical Research and Project Institute (EVPU) in Nova Dubnica and obtained results are presented with kind permission of this Institution.

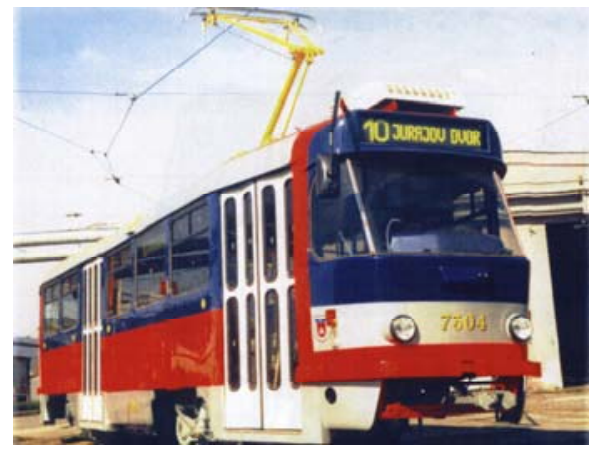

Fig. 19: Modernized tram T3 MOD. 7304.

In Fig. 20 the waveforms for choke current $i_{L 1}(B)$ and output voltage (A) in the transistor $\mathrm{T}_{2}$ are presented. The input voltage is $420 \mathrm{~V}$ and output voltage $770 \mathrm{~V}$.Oscillogram in Fig. 21 is mapping run-up of chopper in vain. Chopper is starting automatically at the $420 \mathrm{~V}$ of input voltage. It is making an effort of stabilization inter-circuit voltage on 770 $\mathrm{V}$. In the instant time, when is amount to inter-circuit current rated value $770 \mathrm{~V}$, current no-load converter is decreasing anon to zero. In Fig. 22 and Fig. 23 the waveforms for recuperative (step-down) converter are presented.

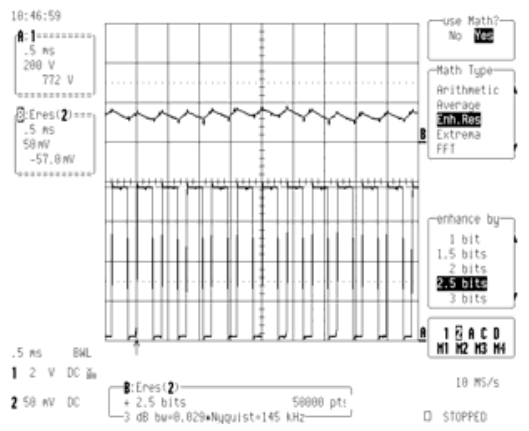

Fig. 20: Input current (waveform B) and output voltage (waveform A) of the active filter.

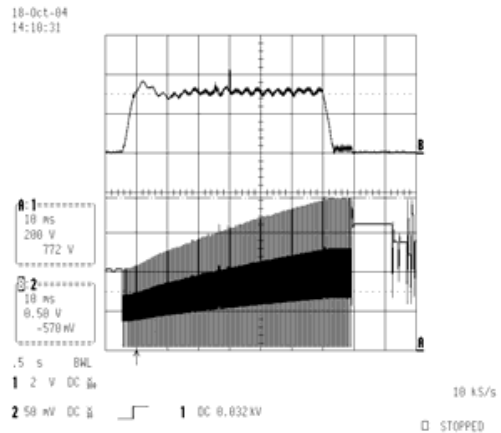

Fig. 21: Run-up chopper in vain.

Waveform envelope is introduced actually voltage of DC inter-circuit (upper bound) and trolley voltage (zero or short - circuit, lower bound). It is evident at the instant time $42 \mathrm{~ms}$ : the inter-circuit voltage decreasing under required voltage (around $750 \mathrm{~V}$ ). Voltage regulator decreases the impulse width to zero. If the recuperative energy is continue flowing through the DC inter-circuit the maximum converter current can not strain a point the maximum current of link switcher. During this regulation the maximum value for converter current can be change. Basically on this principle the regulation of output voltage was realized.

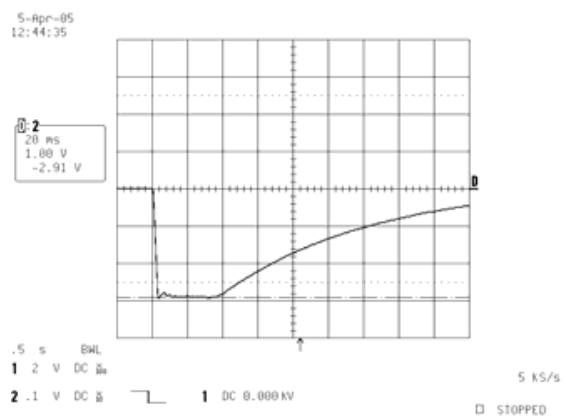

Fig. 22: Waveform for the recuperative (negative) trolley current.

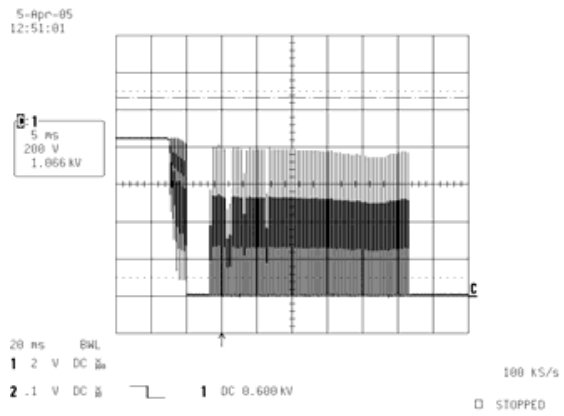

Fig. 21: Input converter voltage.

The other measurements were realized for main converter and input filter (Fig. 24) during tram drive and braking mode. The test was realized on 450 meters long way. Obtained results are presented in Fig. 25. In these waveforms the measurement for different output load during drive mode was realized. In braking mode the recuperative and resistive braking was measured. 


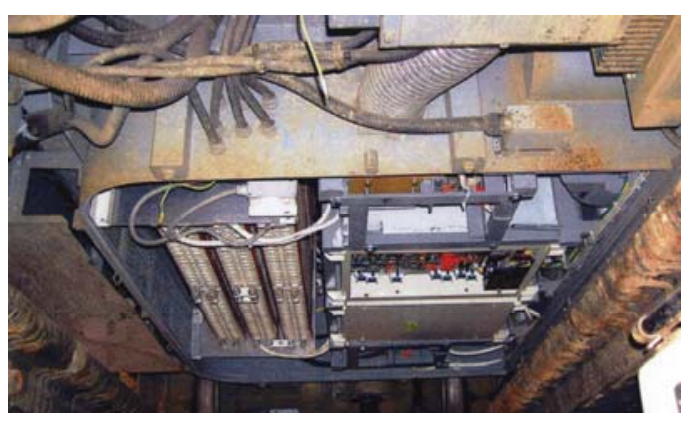

Fig. 24: Main converters container KHM 250 sub floor of tram T3 MOD 7304.

The maximum velocity in drive mode was $\mathrm{v}_{\max }=70 \mathrm{~km} /$ hour. The tram is achieved this velocity behind 24 - 26 second.

The velocity was determined basically on achieved converter frequency. Obtained results are presented in Fig. 23. In velocity waveform is possible seen the electronic speed restriction. This restriction is connected with decreasing of required and measured currents for individual motor group.

In Fig. 25 the nominal current through chopper is presented too. There is possible see all three different active states for drive, run-out and braking mode during one measurement. Current range is between 320A and -260A. This nominal current has similar waveform as the required moment measured for motor system. Difference is only in value and during run-out motor mode. This mode is active between 25 and 30 second. The chopper current is increasing above the $300 \mathrm{~A}$. At the same time the required moment is slowly decreasing to $4000 \mathrm{~N} / \mathrm{m}$.

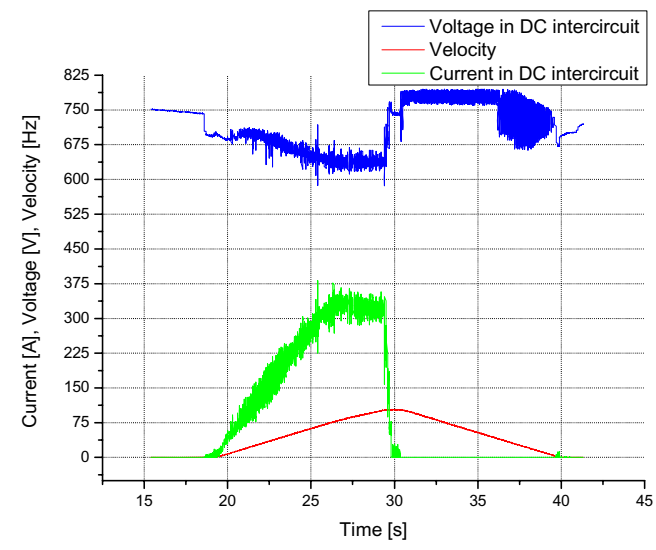

Fig. 25: Drive and braking mode measurement. Blue colour - decreasing and icreasing of DC inter-circuit voltage, green colour - current in DC inter-circuit, red colour - measured velocity in $\mathrm{Hz}$.

\section{CONCLUSION}

This paper deals with design and measurement of the input active filter with changes of output loads and fluctuating input power supply. In paper two different stabilization methods and their simulation results are presented. The classical offset method and the new approach for output voltage stabilization with super-capacitors are presented. The main differences between these two methods are in output voltage waveforms. For stabilization method with supercapacitor power tank the voltage waveform is much more stable. Its range is between $730 \mathrm{~V}$ and $810 \mathrm{~V}$. In comparison with offset method (the range is between $650 \mathrm{~V}$ and $810 \mathrm{~V}$ ) the method with super-capacitors as an energy buffer has better results. In solution the stabilization of nominal current value in link switcher must be kept (link switcher value is $750 \mathrm{~A})$. The output voltage value is charged during run-out mode $(800 \mathrm{~V}$ source connected with output load in series). Finally the real measurement was realized. As results the voltage and current waveforms on filter choke and capacitor for multiple working modes was described.

\section{REFERENCES}

[1] Maxwell Technologies, Inc., "Peak Load Shaving in a Fuel Cell Powered Industrial Servo System”, Application Note, Document 1007234 Rev 2, 10/04.

[2] Rufer, A.: "Key developments for supercapacitive energy storage: Power electronic converters, system and control", In Power Convertion and Inteligent Moion 2001, Nuremberg, Germany, June 2001, PCIM-2001.

[3] Barade, P., Rufer, A.: "A supercapacitor-based energy storage system for elevators with soft commutated interface”, In IAS: 36th IEEE Industry Application Society Annual Meeting, Hyatt Regency Hotel, Chicago, Illinois, USA, October 2001, IAS-IEEE.

[4] Maxwell Technologies, Inc., "How to Determine the Appropriate Size Ultracapacitor for Your Application", Application Note, Document 1007236 Rev 2, 10/04.

[5] Maxwell Technologies, Inc., "Electric Double Layer Capacitor: BMOD Ultracapacitor Modules", Application Note, Document 1008145 Rev 1.

[6] Mohan, N., Underland, T.M., Robbins, W.P.: "Power Electronics”, John Wiley, N.York, 1995.

[7] Jansa, F.: "Vozidla elektricke trakce, (Electric Traction Vehicles, in Czech)", Praha SNTL 1987.

[8] Temesi, E., Frisch, M., Sontheimer, P.: "Active PFC with Modules", Magazine Power Systems Design Europe, June 04

[9] Racek, V.: "Current and Voltage Circumstances in DC Pulse Converter Supplied from a Source with Great Inductance", EPE Journal, vol.4, 1994 No1, pp.29-35.

[10] Sitar, J., Racek, V., Havrila, R., Gerek, I.: "Input Active Filter for the DC/DC Converter Supplied from the Traction Trolley Net", 11th European Conference on Power Electronics and Applications, EPE 2005, 11-14.9.2005, Dresden, ISBN: 90-75815-08-5, IEEE Catalog Number: 05EX1132C.

[11] Racek, V., Sitar, J., Gerek, I., Kulha, P.: "Design of Tram Active Filter at Fluctuating Power Supply in Trolley Net and Various Output Loads", IEEE International Conference on Industrial Technology, IEEE ICIT2005, 14-17.11.2005, Hong Kong, City University of Hong Kong, IEEE Catalog Number: 05TH8844C, ISBN 0-7803-9484-4, Library of Congress: 20005932324.

[12] Havrila, R., Dobrucky, B., Balazovic, P.: "Matrix converter synchronous motor drive”, EPE 2001, Graz, Austria, August 27-29, 2001.

[13] Havrila, R.; Dobrucky, B.; Balazovic, P.: "Matrix converter synchronous motor drive”, EPE 2001, Graz, Austria, August 27-29, 2001, EPE 2001, Graz, Austria, August 27-29, 2001.

[14] www.caspoc.com.

[15] Maga D., Rerucha V., Halgos J.: "Hightorque Stepper Machine and Its 3-D model in Ansys", In: Journal Cybernetics Letter, Informatics, Cybernetics and Robotics, FVT UO Brno, Czech Republic, ISSN 1802-3525, (www.cybletter.com).

[16] Maga, D., Hartansky. R.: Numerical Solution, 1. issue, Brno, University of Defense, 2006, p. 174, ISBN 80-7231-130-1. 